Received: July 012014 | Accepted after revision: Nov 252014 | First published online: Jan 222015

Statement of interest: Disclosures can be found alongside the online version of this article at erj.ersjournals.com

Support statement: This study was supported by Investigator Initiated Research funding from Pfizer Inc. and in part by the Intramural Research Programme (National Institute of Allergy and Infectious Diseases (NIAID)). Funding information for this article has been deposited with FundRef.

\title{
References
}

1 Adjemian J, Olivier KN, Seitz AE, et al. Prevalence of nontuberculous mycobacterial lung disease in US medicare beneficiaries. Am J Respir Crit Care Med 2012; 185: 881-886.

2 CDC. Reported tuberculosis in the United States, 2012. Atlanta, US Department of Health and Human Services, 2013.

3 Lee M, Lee J, Carroll MW, et al. Linezolid for treatment of chronic extensively drug-resistant tuberculosis. $N$ Engl J Med 2012; 367: 1508-1518.

4 Schecter GF, Scott C, True L, et al. Linezolid in the treatment of multidrug-resistant tuberculosis. Clin Infect Dis 2010; 50: 49-55.

5 Migliori GB, Eker B, Richardson MD, et al. A retrospective TBNET assessment of linezolid safety, tolerability and efficacy in multidrug-resistant tuberculosis. Eur Respir J 2009; 34: 387-393.

6 Sotgiu G, Centis R, D'Ambrosio L, et al. Efficacy, safety and tolerability of linezolid containing regimens in treating MDR-TB and XDR-TB: systematic review and meta-analysis. Eur Respir J 2012; 40: 1430-1442.

7 Sotgiu G, Centis R, D’Ambrosio L, et al. Linezolid to treat extensively drug-resistant TB: retrospective data are confirmed by experimental evidence. Eur Respir J 2013; 42: 288-290.

8 Cox H, Ford N. Linezolid for the treatment of complicated drug-resistant tuberculosis: a systematic review and meta-analysis. Int J Tuberc Lung Dis 2012; 16: 447-454.

9 Vinh DC, Rubinstein E. Linezolid: a review of safety and tolerability. J Infect 2009; 59: Suppl. 1, S59-S74.

10 Bishop E, Melvani S, Howden BP, et al. Good clinical outcomes but high rates of adverse reactions during linezolid therapy for serious infections: a proposed protocol for monitoring therapy in complex patients. Antimicrob Agents Chemother 2006; 50: 1599-1602.

11 Koh WJ, Kang YR, Jeon K, et al. Daily $300 \mathrm{mg}$ dose of linezolid for multidrug-resistant and extensively drug-resistant tuberculosis: updated analysis of 51 patients. J Antimicrob Chemother 2012; 67: 1503-1507.

12 Rey-Jurado E, Tudo G, de la Bellacasa JP, et al. In vitro effect of three-drug combinations of antituberculous agents against multidrug-resistant mycobacterium tuberculosis isolates. Int J Antimicrob Agents 2013; 41: 278-280.

13 Guna R, Munoz C, Dominguez V, et al. In vitro activity of linezolid, clarithromycin and moxifloxacin against clinical isolates of mycobacterium kansasii. J Antimicrob Chemother 2005; 55: 950-953.

14 Wallace RJJr, Brown-Elliott BA, Ward SC, et al. Activities of linezolid against rapidly growing mycobacteria. Antimicrob Agents Chemother 2001; 45: 764-767.

\section{Serious adverse events during a 6-min walk test in patients with pulmonary hypertension}

\section{To the Editor:}

The 6-min walk test (6MWT) is well standardised and, as per current guidelines, is deemed safe to perform in a range of patients [1]. In pulmonary arterial hypertension (PAH), 6-min walk distance (6MWD) is an important predictor of mortality and morbidity [2]. Moreover, changes in the 6MWD have been the primary end-point of most pivotal randomised controlled trials that have assessed the clinical response to specific pharmacological therapies in PAH [2].

To date there have been no published reports about the serious adverse events associated with the 6MWT, e.g. death, life-threatening events, inpatient hospitalisation or prolongation of existing hospitalisation, persistent or significant incapacity, and substantial disruption to the ability to conduct normal life [3]. Perhaps the best reported study that supports the safety of the 6MWT is that of ENRIGHT et al. [4], which was performed in over 2000 elderly subjects ( $77 \pm 4$ years of age) with a range of comorbidities. The authors reported no serious adverse events during the 6MWT, and whilst some participants stopped the test with chest pain, no emergency evaluation or therapy was required. More recently, in a review of 741 stable lung disease patients, 


\begin{tabular}{|c|c|c|c|}
\hline & Case 1 & Case 2 & Case 3 \\
\hline \multicolumn{4}{|l|}{ 6MWT } \\
\hline When completed & 3 months prior & 3 months prior & 5 months prior \\
\hline 6-min walk distance $\mathrm{m}$ & 393 & 570 & 645 \\
\hline Use of oxygen & Yes $\left(2 \mathrm{~L} \cdot \mathrm{min}^{-1}\right)$ & No & No \\
\hline End exercise $\mathrm{SpO}_{2} \%$ & 76 & 79 & 90 \\
\hline End exercise HR beats $\cdot \mathrm{min}^{-1}$ & 129 & 127 & 155 \\
\hline End exercise dyspnoea $(0-10)$ & 4 & 2 & 5 \\
\hline Rests $\mathrm{n}$ & 0 & 0 & 0 \\
\hline \multicolumn{4}{|l|}{ Echocardiography } \\
\hline When completed & 3 months prior & 3 months prior & 6 months prior \\
\hline LVEF \% & 45 & 41 & 52 \\
\hline $\mathrm{RA}$ area $\mathrm{cm}^{2}$ & 30 & 31 & 33 \\
\hline LA area $\mathrm{cm}^{2}$ & 19 & 15 & 26 \\
\hline RVSP mmHg & 95 & 72 & 100 \\
\hline TAPSE mm & & 10 & 12 \\
\hline RV dilatation & Severe & Severe & Severe \\
\hline RV dysfunction & Severe & Severe & Severe \\
\hline \multicolumn{4}{|l|}{ RHC } \\
\hline When completed & 3 months prior & 3 months prior & 6 months prior \\
\hline mPAP mmHg & 45 & 41 & 37 \\
\hline mPVR Wood units & 7.0 & 12.7 & 7.6 \\
\hline mRAP mmHg & 9 & 14 & 4 \\
\hline $\mathrm{TPG} \mathrm{mmHg}$ & 30 & 28 & 29 \\
\hline PCWP $\mathrm{mmHg}$ & 15 & 10 & 8 \\
\hline Cardiac index $\mathrm{L} \cdot \mathrm{min}^{-1} \cdot \mathrm{m}^{-2}$ & 2.0 & 2.0 & 2.0 \\
\hline Cardiac output L.min ${ }^{-1}$ & 4.3 & 3.43 & 3.8 \\
\hline
\end{tabular}

Tricuspid annular plane systolic (TAPSE) is not reported for case study 1. $\mathrm{SpO}_{2}$ : arterial oxygen saturation measured by pulse oximetry; HR: heart rate; LVEF: left ventricular ejection fraction; RA: right atrium; LA: left atrium; RVSP: right ventricular systolic pressure; mPAP: mean pulmonary artery pressure; mPVR: mean pulmonary vascular resistance; mRAP: mean pulmonary right atrial pressure; TPG: transpulmonary gradient; PCWP: pulmonary capillary wedge pressure.

only $43(6 \%)$ had an adverse event during or immediately after the 6MWT [5]. Notably none of these adverse events would have been classified as serious, with the majority $(n=35)$ being instances in which the test was stopped because patient arterial oxygen saturation measured by pulse oximetry $\left(\mathrm{SpO}_{2}\right)$ dropped below $80 \%$.

Here we report three separate cases of serious adverse events (including one death) during or immediately after 6MWT in which pulmonary hypertension $(\mathrm{PH})$ patients lost consciousness and required emergency attendance. All tests were conducted in a tertiary $\mathrm{PH}$ unit located at a large specialist thoracic hospital in Australia where 15-25 6MWTs are performed each week. In Australia, the 6MWT is routine practice as a requirement for an ongoing pharmaceutical benefit scheme. As per unit policy, the attending physiotherapist walks with the patient and monitors symptoms, heart rate (HR) and $\mathrm{SpO}_{2}$ every minute during the test. Criteria for stopping the test were excessive dyspnoea, diaphoresis, pallor, chest pain, leg pain, dizziness or light-headedness, and an $\mathrm{HR}<50->170$ beats. $\min ^{-1}$ [1]. Note that the unit does not apply a minimal $\mathrm{SpO}_{2}$ for stopping the test as many $\mathrm{PH}$ patients (e.g. those with congenital heart disease) tend to desaturate substantially during the test without accompanying adverse symptoms. Oxygen therapy is administered if resting $\mathrm{SpO}_{2}$ is $<90 \%$ or if the patient is on long-term $\mathrm{O}_{2}$ therapy. Results from the most recent $6 \mathrm{MWT}$, echocardiograph and right heart catheterisation are presented in table 1 for each case study.

Case 1 was a 75-year-old male (New York Heart Association (NYHA) class III) with idiopathic pulmonary fibrosis and severe $\mathrm{PH}$ diagnosed 20 months prior to the event [6]. The patient underwent coronary angiography 1 month prior to the event, and mild coronary artery disease (CAD) (40\% mid-right coronary artery) was demonstrated. Prescribed $\mathrm{PH}$ therapy was ambrisentan, in addition to aspirin, atorvastatin, telsimartan and prazosin. Medication had not changed and the patient had not reported any adverse events since the previous visit. The patient was reviewed by his physician $\sim 1 \mathrm{~h}$ prior to the 6MWT, at which time blood pressure was $130 / 80 \mathrm{mmHg}$, resting HR was 88 beats. $\mathrm{min}^{-1}$ and regular, jugular venous pressure was normal, and resting $\mathrm{SpO}_{2}$ (room air) $89 \%$. 
Medical records note that the patient completed $300 \mathrm{~m}$ at $5 \mathrm{~min}$ into the walk test and that initial $\mathrm{SpO}_{2}$ was stable, declining to $78 \%$. At this point the patient reported dizziness and collapsed. Code was called and CPR commenced; however, ECG rhythm was asystole throughout the 30-min resuscitation period despite intravenous adrenalin, atropine, transcutaneous pacing, intubation and ventilation, and continuous CPR. It was not possible to resuscitate the patient and autopsy was declined.

Case 2 was a 25-year-old female (NYHA class II) with surgically repaired congenital heart disease-associated $\mathrm{PH}$ (common atrium repair at 6 months of age). A permanent pacemaker for sick sinus syndrome/atrial fibrillation was inserted at 6 years of age. The patient was on combination therapy consisting of bosentan, sildenafil and inhaled iloprost. Medication and patient status since the previous 6MWT were unchanged with no adverse events (including syncope) reported during this period.

The patient underwent routine 6MWT. $1 \mathrm{~min}$ post-6MWT the patient collapsed without warning. Immediately after 6MWT the patient had been talking coherently with the physiotherapist and had not reported any light-headedness. CPR commenced and ECG confirmed ventricular fibrillation; the patient and was successfully resuscitated following two direct current shocks. The patient was transferred to the intensive care unit, was confused and was self-ventilating on $8 \mathrm{~L} \cdot \mathrm{min}^{-1} \mathrm{O}_{2}$. Interrogation of the patient's pacemaker post arrest was suggestive of polymorphic ventricular tachycardia secondary to left ventricular dysfunction as a possible cause. Echocardiogram post arrest confirmed severe right ventricular (RV) dysfunction. Coronary angiogram and intravascular ultrasound (IVUS) with exercise excluded CAD and compression of the left main coronary artery (LMCA) from a dilated main pulmonary artery.

Case 3 was a 30-year-old male (NYHA Class II) with inoperable chronic thromboembolic PH who was prescribed combination therapy consisting of bosentan and sildenafil. Patient medication and disease severity had not changed since the previous 6MWT and no serious adverse events had been reported since the previous clinical visit.

The patient had completed $240 \mathrm{~m}$ of the $6 \mathrm{MWT}$ when he suddenly collapsed, lost consciousness and hit his head on the wall. The physiotherapist recorded and reported no warning symptoms of syncope. Code was called and the patient was self-ventilating $\mathrm{SpO}_{2} 90 \%$ at $10 \mathrm{~L} \cdot \mathrm{min}^{-1} \mathrm{O}_{2} \cdot \mathrm{HR}$ and breathing rates were 70 beats $\cdot \mathrm{min}^{-1}$ and 20 breaths $\cdot \mathrm{min}^{-1}$, respectively, and blood pressure was $130 / 80 \mathrm{mmHg}$. There was spontaneous recovery within 2-3 min of the syncopal event and the patient did not require resuscitation. The patient was admitted and monitored. Subsequent coronary angiogram and IVUS with exercise demonstrated atrio-ventricular block and reproduced syncopal symptoms, and exercise testing was ceased. CAD was excluded as was compression of the LMCA from a dilated main pulmonary artery.

This study is novel as it is the first time that significant adverse events such as death or a life-threatening adverse event requiring hospitalisation have been reported as the result of conducting a 6MWT in any patient. None of the case studies met the current absolute contraindications to undertake the 6MWT, i.e. there was no history of unstable angina or heart attack in the previous month [1].

Whilst other studies have reported adverse events with the 6MWT, none of these events would be classified as a serious adverse event $[4,5,7]$. Our findings suggest that $\mathrm{PH}$ patients may be more at risk of serious adverse events during routine exercise tests such as the 6MWT.

Only one of the case studies had a pre-existing cardiac arrhythmia; however, this was paced. Whilst the incidence of cardiac arrhythmia in $\mathrm{PH}$ is well documented, the incidence of ventricular fibrillation is quite low [8]. In their study of $132 \mathrm{PAH}$ patients who required CPR, HoEPer et al. [9] reported that only 10 had ventricular fibrillation (8\%), whereas $58(45 \%)$ patients had bradycardia, suggesting that bradycardia (which is inappropriate to the clinical scenario) is also a poor prognostic sign [10]. No evidence of bradycardia prior to $6 \mathrm{MWT}$ was seen in our case studies.

Whilst our subjects desaturated during the exercise test, it is unclear whether this degree of hypoxia is related to their arrhythmia. In a group of 19 interstitial lung disease patients, PARK et al. [11] reported that 11 patients desaturated to $<80 \%$ during the $6 \mathrm{MWT}$. This level of desaturation was less than that reported during 24-h monitoring of $\mathrm{SpO}_{2}$. Moreover, none of the patients had a significant arrhythmia during the 6MWT but they all exhibited arrhythmias during the day. These daily arrhythmias were unrelated to the hypoxic state of the patients.

Whilst current recommendations would appear to suggest that minimal clinical supervision is required for the 6MWT, our results add a note of caution for patients with diagnosed PH. In each of the cases, the patients demonstrated severe RV dysfunction (table 1). Unlike other chronic heart and lung disease patients, $\mathrm{PH}$ patients appear more unstable and may warrant additional screening prior to undertaking a $6 \mathrm{MWT}$. It is worth nothing that during a retrospective audit of $>12006 \mathrm{MWT}$ in our clinic, we discovered a further two patients who had syncopal events during their 6MWT. Neither of these required 
resuscitation. Each case reported having syncopal events in the 3 months prior to their $6 \mathrm{MWT}$. As a result, our clinical practice for the performance of a $6 \mathrm{MWT}$ has been modified to include a pre-screening medical questionnaire for events such as syncope, chest infection and change of medication as examples of an absolute contraindication to the conduct of 6MWT.

In summary, we have reported three separate cases of serious adverse events during the 6MWT in patients with severe RV dysfunction secondary to PH. Given that this appears to be the first time serious adverse events of this nature have been reported, we would argue there should be additional caution when exercise testing of any form (including shuttle walk test and supervised cardiopulmonary exercise test) is undertaken in individuals with severe RV dysfunction associated with $\mathrm{PH}$.

\section{@ERSpublications \\ The first ever reported cases of serious adverse events during the 6MWT in patients with pulmonary hypertension http://ow.ly/FdVp8}

Norman R. Morris ${ }^{1,2}$, Helen Seale ${ }^{2}$, Julie Harris ${ }^{2}$, Kathleen Hall ${ }^{2}$, Peter Hopkins ${ }^{2}$ and Fiona Kermeen ${ }^{2}$

${ }^{1}$ School of Allied Health Sciences and Griffith Health Institute, Griffith University, Gold Coast, Australia. ${ }^{2}$ Queensland Lung Transplant Service, The Prince Charles Hospital, Brisbane, Australia.

Correspondence: Norman R. Morris, School of Allied Health Sciences and Griffith Health Institute, Griffith University, Gold Coast, Australia.

E-mail: n.morris@griffith.edu.au

Received: Aug 102014 | Accepted after revision: Nov 242014 | First published online: Jan 222015

Conflict of interest: None declared.

Acknowledgements: The authors would like to thank Associate Professor Anne Holland (La Trobe University, Melbourne, Australia) for her comments on this manuscript.

\section{References}

1 American Thoracic Society. ATS statement: guidelines for the six-minute walk test. Am J Respir Crit Care Med 2002; 166: 111-117.

2 Galiè N, Corris PA, Frost A, et al. Updated treatment algorithm of pulmonary arterial hypertension. J Am Coll Cardiol 2013; 62: Suppl. 25, D60-D72.

3 USFDA. Code of Federal Regulations Title 21, Volume 5. Food and Drug Administration Department of Health and Human Services Subchapter D - Drugs for Human Use. http://www.accessdata.fda.gov/scripts/cdrh/cfdocs/ cfcfr/cfrsearch.cfm?fr=312.32 Date last updated: April 1, 2014. Date last accessed: July 3, 2014.

4 Enright PL, McBurnie MA, Bittner V, et al. The 6-min walk test: a quick measure of functional status in elderly adults. Chest 2003; 123: 387-398.

5 Jenkins S, Cecins N. Six-minute walk test: observed adverse events and oxygen desaturation in a large cohort of patients with chronic lung disease. Intern Med J 2011; 41: 416-422.

6 Simonneau G, Gatzoulis MA, Adatia I, et al. Updated clinical classification of pulmonary hypertension. J Am Coll Cardiol 2013; 62: Suppl. 25, D34-D41.

7 Ameri A. Six minute walk test in respiratory diseases: a university hospital experience. Ann Thorac Med 2006; 1: $16-19$.

8 Hoeper MM, Bogaard HJ, Condliffe R, et al. Definitions and diagnosis of pulmonary hypertension. J Am Coll Cardiol 2013; 62: Suppl. 25, D42-D50.

9 Hoeper MM, Galié N, Murali S, et al. Outcome after cardiopulmonary resuscitation in patients with pulmonary arterial hypertension. Am J Respir Crit Care Med 2002; 165: 341-344.

10 Rajdev A, Garan H, Biviano A. Arrhythmias in pulmonary arterial hypertension. Prog Cardiovasc Dis 2012; 55: 180-186.

11 Park JH, Jegal Y, Shim TS, et al. Hypoxemia and arrhythmia during daily activities and six-minute walk test in fibrotic interstitial lung diseases. J Korean Med Sci 2011; 26: 372-378. 